Article

\title{
Where and How to Look for Help Matters: Analysis of Support Exchange in Online Health Communities for People Living with HIV
}

\author{
Juan F. Maestre *, Susan C. Herring, Aehong Min ${ }^{\circledR}$, Ciabhan L. Connelly and Patrick C. Shih \\ School of Informatics, Computing, and Engineering, Indiana University Bloomington, \\ Bloomington, IN 47408, USA; herring@indiana.edu (S.C.H.); aemin@iu.edu (A.M.); \\ ciaconne@indiana.edu (C.L.C.); patshih@indiana.edu (P.C.S.) \\ * Correspondence: jmaestre@indiana.edu
}

Received: 28 September 2018; Accepted: 18 October 2018; Published: 20 October 2018

\begin{abstract}
Research is scarce on how direct and indirect support seeking strategies affect support exchange in online health communities. Moreover, prior research has relied mostly on content analysis of forum posts at the post level. In order to generate a more fine-grained analysis of support exchange, we conducted content analysis at the utterance level, taking directness of support seeking, quality of provision, forum type, and seeker gender into account. Our analysis of four popular online support forums for people living with human immunodeficiency virus found that type of support sought and provided, support seeking strategy, and quality of emotional support provision differed in care provider/formal forums versus social/informal forums. Interestingly, indirect support seeking tended to elicit more supportive emotional responses than direct support seeking strategies in all forums; we account for this in terms of type of support sought. Practical implications for online support communities are discussed.
\end{abstract}

Keywords: support seeking; social support; HIV; HIV support; online health communities; online forums: stigmatized populations; computer-mediated communication; content analysis

\section{Introduction}

Online health communities have made it easier for individuals to access a varied array of problem-focused resources while being honest and open about their feelings and needs without having to worry about embarrassment and time-space constraints [1,2]. In particular, people living with stigmatized conditions such as mental illness, cancer, and HIV are more likely to seek support and health information online due to the perceived anonymity the Internet provides [3-7]. Support exchange (i.e., the seeking, provision, and reception of social support) has been studied at the message content level, focusing on the type and quality of support provided and the positive or negative emotional outcomes for the recipients in both face-to-face ( $\mathrm{FtF})$ [8] and online contexts [9-12]. However, research on how people seek support has been mostly limited to FtF scenarios. The most important finding from FtF support seeking research is that the way in which distressed individuals seek support influences the quality of support they receive in return $[13,14]$. Notably, it has been found that seeking support in a direct way (i.e., stating the problem clearly and asking for help explicitly) leads to better support provision, while indirect seeking (i.e., not stating the problem clearly and not asking for help explicitly) is more likely to get unsupportive responses $[13,15,16]$. However, it is less clear how people seek support in online communities, or the type and quality of support provision online seeking behavior promotes in return. Moreover, the unit of analysis in previous support seeking research has been the entire post or message. This may be problematic, in that a single post could contain multiple acts of support seeking and include both direct and indirect support seeking strategies. 
Online forum participants could even provide support in one part of a message and seek support in another part. Thus, the results of studies that focus on support seeking at the post or message level could conflate potentially important distinctions.

To our knowledge, scant literature has focused on support seeking strategies in online health communities. This is especially true for people living with human immunodeficiency virus (abbreviated as "PLH" henceforth), which is a highly-stigmatized population. According to the United Nations Programme on HIV / AIDS (UNAIDS), in 2015 alone, more than two million people became infected with HIV, totaling 36.7 million PLH worldwide [17]. In the United States, more than one million people are living with HIV, and around 40,000 become infected with the virus each year [18]. Social support is of paramount importance for this population, as it is linked to decreased depression and positive adjustment to the disease [11]. Understandably, PLH have been taking advantage of online health communities for quite some time, especially in the context of support exchange, and many Facebook support groups and online forums currently cater to this population. However, support exchange in online communities for PLH is rarely studied.

In this paper, we contribute to the literature by conducting a content analysis-at the utterance level—of 400 posts collected from four popular online support forums for PLH. In the following sections, we review literature on social support research in $\mathrm{FtF}$ and online contexts, explain the method employed in our study, present results, and conclude with discussion, implications, and directions for future research.

\section{Literature Review}

\subsection{Social Support}

Social support consists of the verbal and nonverbal behaviors that aim to help and assist others who are in a state of distress. A supportive interaction is characterized by the presence of three supportive moments: seeking, provision, and reception [19]. Studies of social support continue to corroborate the positive impact that social support has on recipients' physical and psychological health by allowing recipients to cope better with stressful and problematic events in their lives [20].

The social support behavior code developed by Cutrona and Suhr [21] identifies five types of social support: emotional, informational, tangible/instrumental, self-esteem, and network. Emotional support is defined as "specific lines of communicative behavior enacted by one party with the intent of helping another cope effectively with emotional distress" [22]. Informational support is understood as behaviors that provide advice, guidance, and facts in order to help someone solve or manage a problem $[23,24]$. Self-esteem support "is a particular type of emotional support that is provided with the intent of enhancing how others feel about themselves and their attributes, abilities and accomplishments" [25]. Tangible/instrumental support refers to material aid or monetary assistance [11,24]. Finally, network support expands or reinforces a support seeker's social connections [24].

Emotional support in particular has received a great deal of attention by scholars studying social support communication due to the prevalence of this type of support in FtF scenarios. Burleson [26] proposed a dual-process theory of supportive communication outcomes, which takes into account the verbal person centeredness (VPC) in emotional supportive messages, the recipient's cognitive complexity and motivation to process supportive messages, and the outcomes of the supportive intervention (message outcomes). VPC refers to the extent to which messages acknowledge and legitimize the feelings and perspective of the recipient. VPC has also been found to be associated with quality of support provided $[8,27]$. In brief, the theory proposes that, when messages receive a high level of scrutiny from receivers, the outcomes will be influenced mainly by the VPC of the messages [28]. 


\subsection{Social Support Seeking}

Research on support seeking is relatively scarce, and it has focused on understanding the ways individuals seek support in distressing situations. Formally, support seeking is defined as "intentional communicative activity with the aim of eliciting supportive action from others" [19]. Barbee and Cunningham [15] posit that support seeking behaviors influence the quality of support provision. They propose a Support Activation Behavior Coding System which identifies two types of support seeking strategies: direct and indirect. On one hand, a direct support seeking strategy is explicit. Individuals seeking support directly describe the problem in more detail and produce a clear request for help (i.e., by asking for assistance explicitly). Research has shown that, when people request support directly, their requests are more likely to be met with approach rather than with avoidance from others [13] and more supportive responses from providers [29,30]. On the other hand, an indirect support seeking strategy is less explicit. Individuals seeking support indirectly may complain or hint about a problem, minimize the problem, and/or change the topic. The supportive response may be negatively affected, if support providers feel unsure on how to provide support due to the ambiguity of indirect support seeking requests [15]. Consequently, direct support seeking strategies have been linked with a better quality of support provision $[15,31]$. The methods used most in support seeking studies are self-report questionnaires and structured interviews with support recipients, during which the recipients recall situations when they sought support from others (e.g., $[13,16])$.

Individuals do not always seek support directly, even though direct support seeking is linked with favorable or positive outcomes. Characteristics of support providers, support receivers, and the context of the supportive interaction may all impact the directness of support seeking. For instance, social status, self-esteem, face threatening situations, gender, and anticipated social rejection may lead to indirect support seeking [15]. Moreover, anticipation of social rejection has been linked to perceptions of stigma and support seeking behaviors. For instance, Williams and Mickelson [13] conducted a study with women living in poverty and found that the more the women perceived stigma about their condition, the more they engaged in indirect seeking behaviors. Indirect seeking was always linked to less supportive responses. Similarly, studies involving PLH have found that direct support seeking strategies were linked to better support provision [31], and feelings of stigma negatively affected support seeking [14] and support provision [32] due to difficulties self-disclosing HIV status to others. PLH need social support in order to improve both their physical and psychological health. However, in spite of being so beneficial, many PLH do not attend FtF social support groups due to HIV-related stigma [5,33]. Hence, many PLH have turned to computer-mediated support groups to exchange support with others in a space where they perceive they can control their level of anonymity and privacy.

\subsection{Computer-Mediated Social Support (CMSS)}

Recent studies have been evaluating how social support communication takes place in online environments. CMSS has allowed people-especially those with health-related and stigmatized conditions-to compensate for a lack of access to information and difficulty in forming offline relationships with others who share the same condition [6,34]. The anonymity and privacy provided by computer-mediated environments have been found to be key factors that facilitate self-disclosure, which has been linked to beneficial health outcomes; they motivate individuals to reach out for support and information without fear of being judged, isolated, or victimized $[1,35,36]$. For instance, studies of online cancer support communities have reported positive effects on patients, namely, positive reframing (assessing a difficult situation from a more positive perspective), improved psychological health [10,12], increased emotional well-being, and overall reduction of concerns [10]. Those who participate more in computer-mediated communication by posting and reading messages may come to terms with their condition and feel a greater sense of control, making it easier to find social support and resources-which may not be easily available in offline settings- that help them cope better with their condition and improve their overall well-being [37]. 
The majority of CMSS analyses have turned to automated or manual text content analysis methods applied to messages or posts in order to understand how social support is exchanged in online health communities such as social media networks and online forums (e.g., $[9,11,38])$. For instance, Wang et al. employed machine learning-based methods to automatically identify emotional and informational support in messages posted to an online support group for breast cancer patients and to correlate their prevalence with online group member retention. The researchers found that "the more emotional support members were exposed to the lower the risk of dropout". Informational support did not have the same effects on member commitment [39]. Other studies have used manual content analysis methods to analyze the presence and prevalence of other types of social support messages. A meta-analytic review of 41 studies using manual content analyses to identify types of support in online support messages among individuals coping with illness (including HIV) revealed that informational support, followed by emotional support, were the most prevalent types of support provided online [24]. In the case of studies trying to understand social support exchange in online communities for PLH, the methods commonly employed have been content analysis of online forums where the unit of analysis was an entire message and online surveys directed to users of online forums (e.g, $[3,11,12,40])$. The main findings of these studies have been the positive effects that social support exchange has on the individual's health and the generally high prevalence of informational and emotional support in online health communities.

Although CMSS studies have mainly analyzed emotional support provision and reception and have identified the types of support that are provided most often in online communities, to our knowledge, studies of social support seeking remain limited in research regarding online health communities. The existing studies have employed content analysis of forum messages at the post level in order to assess the overall type of support seeking strategy used and its prevalence in social media for stigmatized conditions such as sexual abuse [9] and HIV. The HIV findings are rather superficial and mainly suggest that, in general, indirect support seeking is more prevalent than direct support seeking [5].

\subsection{Research Questions and Hypothesis}

In order to validate previous findings and advance research on online support seeking in HIV contexts, we address the following research questions:

RQ1: What type of support is sought/provided most often in the HIV support online forums?

RQ2: What differences, if any, are there in support seeking and provision between the informal and formal forums?

RQ3: What type of support seeking strategy is used most often in the online forums?

RQ4: What differences, if any, are there in support seeking and provision between male and female users?

Since the perceived anonymity of the online forums promotes more self-disclosure, we advance the following hypothesis:

H1: People living with HIV will engage in more direct than indirect support seeking in the online forums.

Finally, as direct support seeking has been found to promote more supportive responses, we posit that, for emotional support, direct support seeking will lead to supportive messages with a high level of VPC. Thus,

H2: Direct support seeking will generate supportive messages with a high level of VPC. 


\section{Methodology}

\subsection{Data Source and Sample}

Since online forums are a popular web genre used for online HIV support, a Google search with the keywords "HIV" and "support" was conducted to identify forums for analysis. In order to be included in our sample, a forum had to satisfy the following requirements: (1) the contents of the posts had to be publicly available, (2) there had to have been recent user engagement (i.e., the last thread had to be no older than three months), (3) there had to be a "living with HIV" forum topic, and (4) there had to be at least one reply from another user in any of the most recent 10 threads, as assessed through a brief examination of the threads. In addition, we sought to include forums that are care provider/formal sites (i.e., managed/monitored mostly by care providers) as well as social/informal sites (i.e., managed/monitored mostly by PLH), since both types are popular among PLH. Four forums satisfied all the requirements and are listed in Table 1.

Table 1. Online HIV support forums.

\begin{tabular}{cc}
\hline Type & Forum \\
\hline Social/Informal (SF) & $\begin{array}{c}\text { +SupportGroups [41] } \\
\text { Poz Forums [42] }\end{array}$ \\
\hline Care Provider/Formal (CF) & $\begin{array}{c}\text { MedHelp [43] } \\
\text { HealthBoards [44] }\end{array}$ \\
\hline
\end{tabular}

After getting IRB approval (\#1610007365) from our university to conduct the study, we selected the most recent 100 messages from the "living with HIV" topic from each forum for content analysis, which is an analytic method that has been commonly used in previous related research (e.g., $[9,11])$. A block consists of an author's initial post and replies from other users. The sample contains a total of 154 such blocks.

\subsection{Procedure and Variables}

All data were stored in a spreadsheet, and the date and username of each message were recorded. Two variables were coded for each message as a whole: gender and type of message.

\subsection{Gender}

Information about the gender of a message author was readily available next to the username in the initial post or inside the username's profile in some cases. Gender was also inferred from the textual content of the message (e.g., I am the only man in the house), the name in the signoff (e.g., Love, Mary), or the username (e.g., JamesD1991). If author gender could not be determined in any of these ways, the value "unknown" was assigned for this variable. Otherwise, the possible values are "female" or "male."

\subsection{Type of Message}

The possible values for this variable are "post" or "reply." A "post" is a new message (or initial post) created by a user in a forum topic. A "reply" is a message created by a user (other than the user who posted the initial post) in response to the initial post. Table 2 shows the number of initial posts and replies for each forum type.

The remaining variables were coded at the utterance level. An utterance, as operationalized in this study, corresponds to a sentence or sequence of sentences that communicates a component of a social support exchange (see Table 3). These variables are: support exchange type, type of support provided, type of support sought, support seeking strategy, and level of person-centeredness, as described below. We focus in this study on support seeking and support provision, as the majority of the support 
exchange utterances in our data belong to one or the other of these two types. The coding was selective; that is, only utterances that met the operational criteria for each variable were assigned a value for that variable.

Table 2. Message type by forum type.

\begin{tabular}{cccc}
\hline Forum Type & Posts & Replies & Total \\
\hline CF & 89 & 111 & 200 \\
SF & 65 & 135 & 200 \\
Combined & 154 & 246 & 400 \\
\hline
\end{tabular}

Table 3. Coding of a sample forum message.

\begin{tabular}{|c|c|}
\hline \multicolumn{2}{|c|}{ Message-Level Coding: } \\
\hline $\begin{array}{l}\text { Gender: Male } \\
\text { Type of message: Post }\end{array}$ & \\
\hline \multicolumn{2}{|c|}{ Utterance-Level Coding: } \\
\hline U1: ..That make me start to worry... & $\begin{array}{l}\text { - SET: support seeking } \\
\text { - TSP: n/a } \\
\text { - SSS: indirect } \\
\text { - TSS: emotional } \\
\text { - VPC: } \mathrm{n} / \mathrm{a}\end{array}$ \\
\hline $\begin{array}{l}\text { U2: ..I would like to know is it advisable to } \\
\text { start on my ChemoTherapy where my CD } 4 \\
\text { is so low? }\end{array}$ & $\begin{array}{l}\text { - SET: support seeking } \\
\text { - TSP: n/a } \\
\text { - SSS: direct } \\
\text { - TSS: informational } \\
\text { - VPC: } \mathrm{n} / \mathrm{a}\end{array}$ \\
\hline
\end{tabular}

\subsection{Support Exchange Type (SET)}

The values for this variable are "seeking" or "provision" of support. Utterances were coded with the value "seeking" if their textual content indicated direct or indirect support seeking (see the operationalization of the seeking strategy below for further details). Utterances were coded with the value "provision" if their textual content provided support (e.g., I'm sorry that you are going through that). Finally, a value of "other" was assigned to an utterance that could not be assigned a value of "seeking" or "provision" because its textual content was not related to any type of support exchange (e.g., my name is Tod), or if their textual content acknowledged receiving support (e.g., thank you for the advice).

\subsection{Type of Support Sought/Provided (TSS/TSP)}

Based on the five types of social support explained in the related work section, the possible values for this variable are emotional, informational, self-esteem, tangible/instrumental, or network for both utterances providing and seeking each type of support. Examples of such utterances can be found in Table 4 . 
Table 4. Examples of utterances by support type.

\begin{tabular}{ll}
\hline Support Type & Seeking (s)/Provision (p) \\
\hline Emotional & $\begin{array}{l}\text { s: I'm still scared } \\
\text { p: I'm sorry that you are going through that }\end{array}$ \\
\hline Informational & $\begin{array}{l}\text { s: are any of the guys with normal CD4 counts and low viral } \\
\text { load considered immunocompromised? } \\
\text { p: You should take a test every } 6 \text { months }\end{array}$ \\
\hline Self-esteem & $\begin{array}{l}\text { s: this morning i got out of bed and said to myself just } i \text { have the } \\
\text { virus dont mean the virus have me!! } \\
p: \text { I like the way you think. It brings to light the fact that one } \\
\text { can get past this and take control of their life again }\end{array}$ \\
\hline Network & $\begin{array}{l}\text { s: anyone on here that lives in X and wants to be friend? } \\
\text { p: I will put you in contact with Dr. X }\end{array}$ \\
\hline Tangible/instrumental & $\begin{array}{l}\text { s: I need money to buy pills } \\
\text { p: I will drop the pills in your mailbox }\end{array}$ \\
\hline
\end{tabular}

\subsection{Support Seeking Strategy (SSS)}

As proposed by the Support Activation Behavior Coding System [15], values for this variable can be "direct" or "indirect". Utterances coded as "direct" have to have text content in which the author explicitly asks for information, help, or assistance in the form of an imperative sentence or a request, or they include the word "advice" or "support" if in a different syntactic form (e.g., is it possible to have a normal relationship with an HIV Positive partner?; I want advice). In contrast, utterances coded as "indirect" have to have text content in which the author does not ask for help explicitly but rather complains, or uses simple statements of need or wishes. For example, in the utterance Not good at all. Just want to die already. Only thing keeping me alive is my child. She is only 3 , there is a complaint without an explicit request for help. In addition, the value of "N/A" was assigned to messages that were coded as "provision," or "other" in the variable "support exchange type" explained above.

\subsection{Verbal Person-Centeredness (VPC)}

VPC refers to the extent to which messages acknowledge and legitimize the feelings and perspective of the recipient. VPC has also been found to be associated with quality of support provided [8,27]. In keeping with Burleson's dual-process theory of supportive communication outcomes [26], utterances were coded for VPC with one of three values. A value of "high" or "HPC" is assigned if the utterance includes a highly person-centered message that explicitly elaborates and recognizes the support seeker's feelings (e.g., Don't worry it's not the end of the world. I know you feel crappy but as time goes by you'll get used to it. HIV is a part of you ... and you are beautiful!! ... Stay strong...). An utterance was coded "moderate" or "MPC" if it implied recognition of the other's feelings (e.g., Don't be afraid. Brother, there as social welfare to help you and advise you what to do. Don't panic), and it was coded as "low" or "LPC" if it included a low person-centered message which ignores or minimizes the support seeker's feelings (e.g., you might just be scared or stressed out overthinking things). Finally, the value of "N/A" was assigned to utterances that were not coded as "provision" for support exchange type and that were not coded as "emotional" for type of support provided.

\subsection{Coding}

A codebook was created for the variables explained above. Table 3 illustrates the coding of a sample message. To measure intercoder reliability, the first author and the second author of this paper independently coded 15 blocks $(\sim 10 \%)$ selected at random from the data sample. There was general agreement on the selection and coding of utterances. Subsequently, another 30 blocks $(\sim 20 \%)$ containing 135 utterances were selected at random for independent coding. Codes were applied taking 
into account the discursive context of the text. Interrater agreement on the overall coding of each utterance was 0.89 using Cohen's kappa coefficient. Following this, the first author completed the coding for the rest of the sample.

\subsection{Statistical Analysis}

To compare types of utterances among forums and gender, we conducted a chi-square test. In our sample of 400 posts, 233 unique users produced 525 utterances. A few users posted more than once, but the content differs across posts and replies as they span a few days to over a year. Most posts contain only one or two utterances that are evenly distributed in different content types. Only seven posts contained more than two utterances (3-7, Mean: 4.14, S.D: 1.46) in a specific content type. As the majority of posts have only one or two utterances, we thus assume independence of units of analysis.

\section{Findings}

Of those messages whose author's gender could be identified, the majority $(66 \%, n=178)$ were posted by males. Men posted $61.4 \%(n=116)$ of the messages in the care provider/formal forums $(\mathrm{CFs})$ and $75.6 \%(n=62)$ of the messages in the social/informal forums (SFs). These numbers are significantly different from the number of messages posted by females $\left(\chi^{2}(1)=5.140, p=0.023\right)$. Across all forums, we identified 525 utterances, of which 292 (55.6\%) were seeking support and 233 (44.4\%) were providing support. As seen in Table 5, utterances in CFs were significantly more likely to seek support compared to utterances in SFs $\left(\chi^{2}(1)=6.253, p=0.012\right)$.

Table 5. Utterances seeking and providing support.

\begin{tabular}{cccc}
\hline Forum Type & Seeking & Provision & Total \\
\hline CF & $176(60.7 \%)$ & $115(39.3 \%)$ & $291(100 \%)$ \\
SF & $116(49.6 \%)$ & $118(50.4 \%)$ & $234(100 \%)$ \\
Combined & $292(55.6 \%)$ & $233(44.4 \%)$ & $525(100 \%)$ \\
\hline
\end{tabular}

\subsection{Support Exchanged}

As shown in Figure 1, informational support was the most common type of support exchanged (sought and provided) across all forums (291, 55.4\%), followed by emotional support (191, 36.4\%), self-esteem support (30,5.7\%), and network support (13, 2.5\%). Tangible/instrumental support was not observed in the sample, and thus this type of support was not taken into account in subsequent analyses. The majority of informational support utterances were posted in the CFs $\left(\chi^{2}(1)=25.414\right.$, $p<0.001)$, while the SFs produced more emotional support utterances than the CFs $\left(\chi^{2}(1)=12.029\right.$, $p=0.001)$, as well as the majority of the self-esteem support utterances $\left(\chi^{2}(1)=11.589, p=0.001\right)$. Overall, the types of support exchanged in CFs and SFs are significantly different $\left(\chi^{2}(3)=37.584\right.$, $p<0.001$ ).

Table 6 gives a breakdown of the types of support sought and provided across the sample. Overall, informational and emotional support were provided the most in both CFs and SFs. For each support type, differences between provision and seeking are significant between CFs and SFs (Seeking: $\chi^{2}(3)=36.542, p<0.001$, Provision: $\left.\chi^{2}(3)=9.454, p=0.024\right)$. Moreover, for support seeking, informational support was sought significantly more in CFs than in $\operatorname{SFs}\left(\chi^{2}(1)=32.270, p<0.001\right)$, whereas emotional support $\left(\chi^{2}(1)=17.936, p<0.001\right)$ and self-esteem support $\left(\chi^{2}(1)=11.450\right.$, $p=0.001)$ were sought more in SFs. 


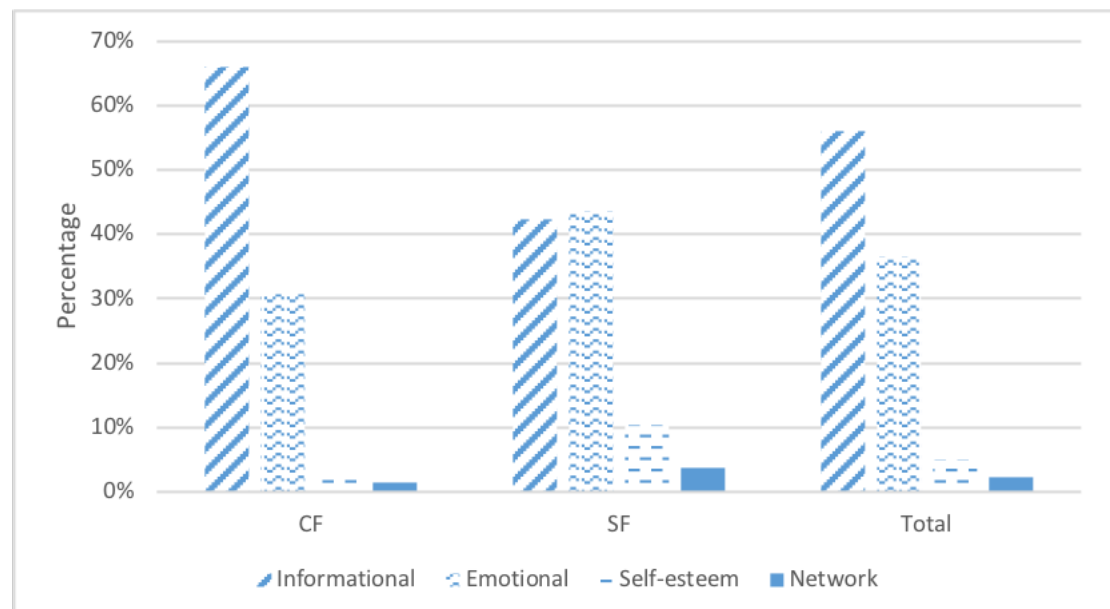

Figure 1. Type of support exchanged.

Table 6. Type of support sought and provided by forum type.

\begin{tabular}{cccccc}
\hline Forum Type & Informational & Emotional & Self-esteem & Network & Total \\
\hline \multicolumn{5}{c}{ Seeking } \\
\hline CF & $123(69.9 \%)$ & $48(27.3 \%)$ & $2(1.1 \%)$ & $3(1.7 \%)$ & $176(100 \%)$ \\
SF & $42(36.2 \%)$ & $60(51.7 \%)$ & $11(9.5 \%)$ & $3(2.6 \%)$ & $116(100 \%)$ \\
Total & $165(56.5 \%)$ & $108(37 \%)$ & $13(4.5 \%)$ & $6(2.1 \%)$ & $292(100 \%)$ \\
\hline \multicolumn{5}{c}{ Provision } \\
CF & $69(60 \%)$ & $41(35.7 \%)$ & $4(3.5 \%)$ & $1(0.9 \%)$ & $115(100 \%)$ \\
SF & $57(48.3 \%)$ & $42(35.6 \%)$ & $13(11 \%)$ & $6(5.1 \%)$ & $118(100 \%)$ \\
Total & $126(54.1 \%)$ & $83(35.6 \%)$ & $17(7.3 \%)$ & $7(3 \%)$ & $233(100 \%)$ \\
\hline
\end{tabular}

Table 7 shows the relationship of emotional support provision to person centeredness. Compared to the SFs, more emotional support utterances have a low level of $\operatorname{VPC}\left(\chi^{2}(1)=7.095, p=0.008\right)$ in the CFs. In the SFs, in contrast, the majority of emotional support utterances have a medium level of VPC and are significantly more frequent than the emotional support utterances in the CFs $\left(\chi^{2}(1)=4.620, p=0.032\right)$. Overall, the levels of VPC are significantly different between CFs and SFs $\left(\chi^{2}(2)=7.152, p=0.028\right)$.

Table 7. Provision of emotional support and VPC.

\begin{tabular}{|c|c|c|c|c|}
\hline \multirow[t]{2}{*}{ Forum Type } & \multicolumn{3}{|c|}{ Verbal Person-Centeredness (VPC) } & \multirow[t]{2}{*}{ Total } \\
\hline & HPC & MPC & LPC & \\
\hline CF & $5(11.9 \%)$ & 17 (40.5\%) & $20(47.6 \%)$ & $42(100 \%)$ \\
\hline SF & $7(15.9 \%)$ & $28(63.6 \%)$ & $9(20.5 \%)$ & $44(100 \%)$ \\
\hline
\end{tabular}

HPC: High Person-Centeredness; MPC: Moderate Person-Centeredness; LPC: Low Person-Centeredness.

We further broke down the support seeking and provision in CFs and SFs by gender (see Table 8). Men tended to seek and provide more informational support than women in both the CFs and SFs. In contrast, women provided more emotional support in the SFs. However, these differences between men and women were not statistically significant. 
Table 8. Support type, gender, and forum type. $M$ = Male; $F$ = Female (Unknown gender is excluded).

\begin{tabular}{cccccc}
\hline Gender-Forum Type & Informational & Emotional & Self-Esteem & Network & Total \\
\hline \multicolumn{7}{c}{ Seeking } \\
M-CF & $65(70.7 \%)$ & $24(26.1 \%)$ & $1(1.1 \%)$ & $2(2.2 \%)$ & $92(100 \%)$ \\
M-SF & $15(44.1 \%)$ & $13(38.2 \%)$ & $6(17.6 \%)$ & 0 & $34(100 \%)$ \\
F-CF & $56(68.3 \%)$ & $24(29.3 \%)$ & $1(1.2 \%)$ & $1(1.2 \%)$ & $82(100 \%)$ \\
F-SF & $4(41.7 \%)$ & $5(33.3 \%)$ & $2(16.7 \%)$ & $1(8.3 \%)$ & $12(100 \%)$ \\
\hline M-CF & $49(58.3 \%)$ & $32(38.1 \%)$ & $2(2.4 \%)$ & $1(1.2 \%)$ & $84(100 \%)$ \\
M-SF & $25(59.5 \%)$ & $12(28.6 \%)$ & $3(7.1 \%)$ & $2(4.8 \%)$ & $42(100 \%)$ \\
F-CF & $12(57.1 \%)$ & $8(38.1 \%)$ & $1(4.8 \%)$ & 0 & $21(100 \%)$ \\
F-SF & $3(37.5 \%)$ & $4(50 \%)$ & 0 & $1(12.5 \%)$ & $8(100 \%)$ \\
\hline
\end{tabular}

\subsection{Support Seeking Strategy}

The direct support seeking strategy is the most frequently used across the entire sample $(172,58.9 \%)$ (see Figure 2). Direct support seeking occurred more frequently in CFs $(125,71 \%)$, whereas indirect support seeking occurred more frequently in SFs $(69,59 \%)$, and this difference is statistically significant as well $\left(\chi^{2}(1)=26.878, p<0.001\right)$.

Both men and women used direct strategies in the CFs. In the SFs, though, men posted somewhat more utterances using indirect strategies than women did (see Table 9). However, these differences are not statistically significant.

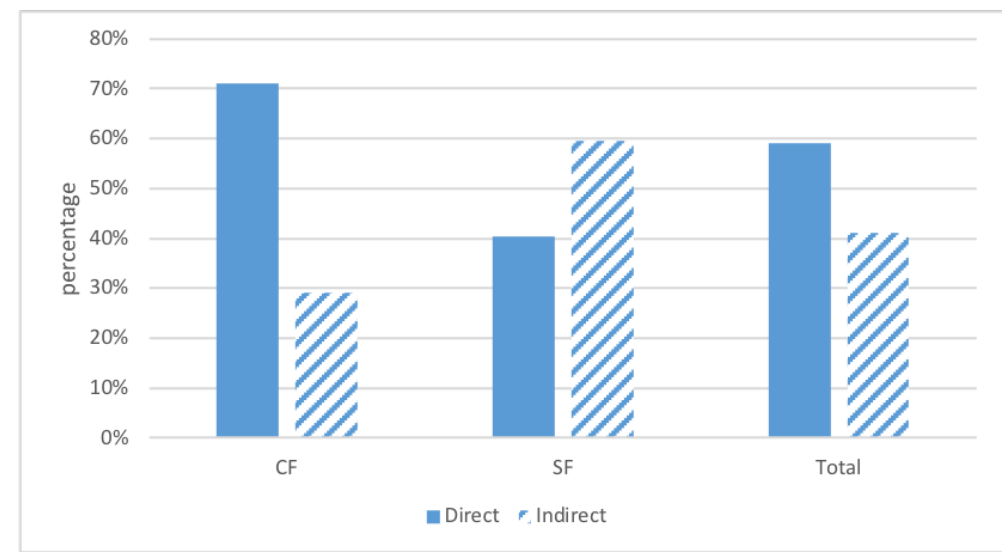

Figure 2. Support seeking strategies by forum type.

Table 9. Support seeking strategy, gender, and forum type. $M=$ Male; $F=$ Female.

\begin{tabular}{cccc}
\hline Gender-Forum Type & Direct & Indirect & Total \\
\hline M-CF & $69(75 \%)$ & $23(25 \%)$ & $92(100 \%)$ \\
M-SF & $17(50 \%)$ & $17(50 \%)$ & $34(100 \%)$ \\
F-CF & $54(65.9 \%)$ & $28(34.1 \%)$ & $82(100 \%)$ \\
F-SF & $5(41.7 \%)$ & $7(58.3 \%)$ & $12(100 \%)$ \\
Total & $145(65.9 \%)$ & $75(34.1 \%)$ & $220(100 \%)$ \\
\hline
\end{tabular}

\subsection{Support Seeking Strategy and Type of Support Provided}

Direct support seeking utterances elicited more social support of all types. However, direct support seeking utterances elicited more informational support $\left(\chi^{2}(1)=105.489, p<0.001\right)$, whereas indirect support seeking utterances elicited more emotional $\left(\chi^{2}(1)=90.519, p<0.001\right)$ and self-esteem 
support $\left(\chi^{2}(1)=10.645, p=0.001\right)$ (see Table 10). In addition, in the case of emotional support provision, direct support seeking elicited responses with a low level of VPC, whereas utterances with indirect support seeking strategies received a greater number of supportive responses with a medium level of VPC (see Table 11). While direct and indirect support seeking are not significantly different for high and low levels of VPC, they are significantly different for medium levels of VPC $\left(\chi^{2}(1)=9.603, p=0.002\right)$. Furthermore, differences in direct support seeking between CFs and SFs are statistically significant for all levels of VPC $\left(\chi^{2}(2)=7.306, p=0.026\right)$.

Table 10. Seeking strategy, type of support provided, and forum type (D = Direct; I = Indirect).

\begin{tabular}{cccccc}
\hline Strategy-Forum Type & Informational & Emotional & Self-Esteem & Network & Total \\
\hline D-CF & $107(85.6 \%)$ & $15(12 \%)$ & 0 & $3(2.4 \%)$ & $125(100 \%)$ \\
D-SF & $33(70.2 \%)$ & $10(21.3 \%)$ & $2(4.3 \%)$ & $2(4.3 \%)$ & $47(100 \%)$ \\
I-CF & $16(31.4 \%)$ & $33(64.7 \%)$ & $2(3.9 \%)$ & 0 & $51(100 \%)$ \\
I-SF & $9(13 \%)$ & $50(72.5 \%)$ & $9(13 \%)$ & $1(1.4 \%)$ & $69(100 \%)$ \\
\hline
\end{tabular}

Table 11. Seeking strategy and level of VPC of emotional support provided (D = Direct; $I$ = Indirect).

\begin{tabular}{|c|c|c|c|c|}
\hline \multirow[t]{2}{*}{ Strategy-Forum Type } & \multicolumn{3}{|c|}{ Verbal Person-centeredness (VPC) } & \multirow[t]{2}{*}{ Total } \\
\hline & HPC & MPC & LPC & \\
\hline $\mathrm{D}-\mathrm{CF}$ & $4(16.7 \%)$ & $6(25 \%)$ & $14(58.3 \%)$ & $24(100 \%)$ \\
\hline D-SF & $6(22.2 \%)$ & $15(55.6 \%)$ & $6(22.2 \%)$ & $27(100 \%)$ \\
\hline $\mathrm{I}-\mathrm{CF}$ & 0 & $6(85.7 \%)$ & $1(14.3 \%)$ & $7(100 \%)$ \\
\hline I-SF & 0 & $7(87.5 \%)$ & $1(12.5 \%)$ & $8(100 \%)$ \\
\hline
\end{tabular}

\section{Discussion}

RQ1 asked, "What type of support is sought/provided most often in the HIV support online forums?" Consistent with previous literature on online health communities, informational, followed by emotional support, was sought and provided the most in the online HIV support forums. However, in SFs, emotional support was sought more. This addresses RQ2, which asked, "What differences, if any, are there in support seeking and provision between the informal and formal forums?" Understandably, messages that included emotional support seeking were more common in SFs, where users discuss feelings more informally. Conversely, messages seeking informational support were found more in $\mathrm{CFs}$, which also makes sense, in that forums hosted on formal sites are more likely to provide information regarding medications and treatments. However, what is perhaps less intuitive is that our findings show that provision of emotional support occurs with a similar frequency in both CFs and SFs, in spite of SFs having more utterances that seek emotional support. This may be because informational support messages often include emotional support, regardless of whether it was sought by the support seeker. For instance, in the support provider's message "The more fiber you have in your diet the better. [I] hope you get some relief", the first part constitutes informational support as sought by the support seeker while the second part of the message provides emotional support. At the same time, as shown in our findings, more of the utterances providing emotional support have a low level of VPC in CFs. This may be due to users in CFs focusing on providing information rather than on elaborating their messages to include emotional support that was not sought by the support seekers in the first place.

RQ3 asked, "What type of support seeking strategy is used most often in the online forums?" Direct support seeking was the most common strategy across the sample. However, there was more direct support seeking in CFs, and more indirect support seeking in SFs, in response to RQ2. This finding appears to be related to the type of support sought in each forum category. The support requested in CFs tends to be informational, for example questions about medication and treatment, which threaten the support seeker's face less than utterances seeking emotional, self-esteem, 
or network support. This is consistent with studies that link stigma with support seeking strategies in online platforms. Andalibi et al. [9] found direct support seeking to be more prevalent than indirect support seeking, and linked direct support seeking with informational support. Similar to other studies, we identified face-saving behaviors in online support groups when discussion of feelings was involved, leading users to seek support indirectly $[5,13]$.

Our findings provide some (limited) support for $\mathrm{H} 2$, in that only direct seeking utterances received HPC responses, as shown in Table 11. However, a different pattern emerges, which contradicts $\mathrm{H} 2$, when we consider the distribution of MPC and LPC responses, which account for the majority of the responses in our data. Overall, messages with direct support seeking utterances tended to elicit more LPC responses, while messages with indirect support seeking utterances elicited more supportive MPC responses. This finding is surprising, in that it does not align with prior work that found that direct support seeking strategies lead to more supportive responses $[13,15]$. One reason for this inconsistency may be that, on the one hand, direct support seeking messages that elicited LPC responses are more characteristic of CFs (as shown in Table 11); thus, it is likely that these messages were asking for informational support, and that, as discussed above, the emotional support component of the support provision may not have been well elaborated, as the support provider may have been focusing on addressing the informational component of the message. On the other hand, the majority of indirect support seeking messages that led to more MPC replies in both CFs and SFs were requesting emotional support, which may have called for a more elaborated emotional response from support providers. These nuances in social support exchange would not have been detected if the messages providing the support had been coded simply as "informational" support at the message or post level, as has been done in prior online social support research.

Finally, RQ4 asked, "What differences, if any, are there in support seeking and provision between male and female users?" Both men and women employed mostly direct support seeking strategies, supporting H1. This could have occurred because more users sought informational support than any other type of support, and information was generally sought directly. In addition, the findings show that men sought and provided more informational support than women overall, while women provided more emotional support in the SFs. This finding is aligned with prior studies on social support and gender that indicate that women tend to seek and provide more emotional support than men [22]. However, women did not participate proportionately more than men in the SFs. Men created $61.4 \%$ of the messages in CFs and $74.7 \%$ of the messages in SFs, as well as posting the majority of messages overall, consistent with past research findings that men post more than women in public online forums [45]. However, these results reflect the demographics of HIV infection that situate the population of men who have sex with men as the group most likely to be living with HIV.

Our results regarding gender should be interpreted with caution, however, as they were not statistically significant. Furthermore, SFs did not indicate the gender of a post author as explicitly and/or consistently as CFs did. Although every attempt was made to identify the author's gender, as explained in the Methods section, it is possible that our identifications contained errors. This concern could be mitigated in future research by sampling from online health support platforms that make post authors' gender available. Alternatively, research could aim to devise automated analysis methods to detect the gender of commenters, as well as to analyze larger data sets.

Overall, our findings show that support seeking and provision vary according to the type of online support forum. This is important because both CFs and SFs are popular with support seekers. To refer to "online support forums" as if they were a single genre is therefore misleading. Moreover, we do not claim that our findings regarding support seeking/provision are generalizable to other online support forums of each type, as they involve a particular population with a stigmatized condition. Nonetheless, the findings have implications that could positively inform the behavior of moderators and influential support providers in online support forums for people living with stigmatized conditions such as HIV. For instance, people could be trained to recognize the different types of support and the different types of seeking strategies. That knowledge would allow providers, for example, to adjust 
support provision to the type and level of person-centeredness desired, as well as to the type of forum. Furthermore, support seekers could be advised to use a seeking strategy that is conducive to attracting more supportive responses from providers, given the support exchange norms of that particular HIV online support community and taking into account support type, seeking strategy, level of person-centeredness, and gender. Such coaching of seekers and providers could promote interactions in online health communities that are more conducive to positive support outcomes.

\section{Implications}

Based on what has been discussed above, online platforms could integrate an application or a plugin that would be able to recognize the different types of support sought, and give suggestions to providers in real time regarding support types and ways to provide support to the seeker. For example, if a user is asking for information in a post, but has also included utterances that elicit emotional or self-esteem support seeking indirectly, a window could pop up when another user goes to reply to the post (especially for $\mathrm{CFs}$ ), giving suggestions as to how to construct a more supportive response. In the case of support seekers, the system could advise users how to seek support in ways that are conducive to generating supportive responses, depending on the type and support exchange behavior of a particular online community.

Additionally, online communities could integrate algorithms that match support seekers and support providers based on how they usually seek and provide support. Such algorithms would take into account user gender, type of support, seeking strategy, and level of VPC. For example, a support seeker who usually asks for informational support using many utterances that seek other types of support could be matched with a supporter with a similar style of informational support provision that also includes many utterances that elicit the other types of support. Such interventions have the potential to enhance positive support outcomes across online platforms that connect and serve stigmatized populations.

In order to implement such practical implications, we will further investigate social support exchange behavior in online communities by analyzing a larger number of posts with an automated approach. Wang et al. [39], for example, explore the effectiveness of using machine learning to mimic researchers' qualitative codes. Further work would be needed to design an algorithm that reliably simulates a researcher's codes. Similar to Wang et al.'s approach, we could also utilize Amazon Mechanical Turk (MTurk) to code a much larger sample of forum posts at the utterance level, averaging the codes of multiple MTurk workers as recommended by Snow et al. [46] to generate enough training data for this approach to be effective.

\section{Conclusions}

The main contributions of this paper derive from the analysis of how members of a highly stigmatized population seek support in online communities and the type and quality of support provided in return. First, we have contributed to the literature on online support exchanges, which have been studied less often than support seeking and provision in FtF contexts, especially as regards support seeking strategies. Second, we verified and expanded claims from previous research regarding support seeking and provision, and, third, we conducted analysis at the level of utterances rather than messages as a whole, leading to important refinements. For instance, our finding that the predominant type of support exchanged in online health communities is informational reinforces and extends previous findings by adding the important qualification that this result varies by forum type, as does the preference for direct vs. indirect support seeking and the quality of the support provided. Thus, we have shown that, even when online forums address the same health condition, there may still be differences in support exchange that are important to take into consideration before making claims about online support exchange overall. These findings have the potential to help guide the training of HIV support providers and seekers who interact online, as well as inform the design of 
future interactive systems deployed in online communities that could make support exchange more proactive and responsive.

Author Contributions: Conceptualization and Methodology: J.F.M. and S.C.H.; Analysis: J.F.M., S.C.H., A.M. and C.L.C.; Writing-Original Draft Preparation: J.F.M.; Writing-Review: S.C.H., A.M., C.L.C.; Editing: J.F.M., S.C.H. and P.C.S.; Supervision: P.C.S.; Project Administration: P.C.S.

Funding: This research received no external funding.

Acknowledgments: We would like to thank the reviewers for their helpful feedback.

Conflicts of Interest: The authors declare no conflict of interest.

\section{References}

1. Zhang, X.; Liu, S.; Chen, X.; Wang, L.; Gao, B.; Zhu, Q. Health information privacy concerns, antecedents, and information disclosure intention in online health communities. Inf. Manag. 2018, 55, 482-493. [CrossRef]

2. Zhang, X.; Liu, S.; Deng, Z.; Chen, X. Knowledge sharing motivations in online health communities: A comparative study of health professionals and normal users. Comput. Hum. Behav. 2017, 75, 797-810. [CrossRef]

3. Mo, P.K.; Coulson, N.S. Online support group use and psychological health for individuals living with HIV/AIDS. Patient Educ. Couns. 2013, 93, 426-432. [CrossRef] [PubMed]

4. Oh, H.J.; Lee, B. The effect of computer-mediated social support in online communities on patient empowerment and doctor-patient communication. Heal. Commun. 2012, 27, 30-41. [CrossRef] [PubMed]

5. Peterson, J.L. "You have to be positive." Social support processes of an online support group for men living with HIV. Commun. Stud. 2009, 60, 526-541. [CrossRef]

6. $\quad$ Berger, M.; Wagner, T.H.; Baker, L.C. Internet use and stigmatized illness. Soc. Sci. Med. 2005, 61, $1821-1827$. [CrossRef] [PubMed]

7. Fox, S. The Social Life of Health Information. Available online: http://www.pewresearch.org/fact-tank/ 2014/01/15/the-social-life-of-health-information/ (accessed on 20 December 2016).

8. Jones, S. Putting the person into person-centered and immediate emotional support: Emotional change and perceived helper competence as outcomes of comforting in helping situations. Commun. Res. 2004, 31, 338-360. [CrossRef]

9. Andalibi, N.; Haimson, O.L.; De Choudhury, M.; Forte, A. Understanding social media disclosures of sexual abuse through the lenses of support seeking and anonymity. In Proceedings of the CHI Conference on Human Factors in Computing Systems, San Jose, CA, USA, 7-12 May 2016; pp. 3906-3918.

10. Kim, E.; Han, J.Y.; Moon, T.J.; Shaw, B.; Shah, D.V.; McTavish, F.M.; Gustafson, D.H. The process and effect of supportive message expression and reception in online breast cancer support groups. Psycho-Oncology 2012, 21, 531-540. [CrossRef] [PubMed]

11. Coursaris, C.K.; Liu, M. An analysis of social support exchanges in online HIV/AIDS self-help groups. Comput. Hum. Behav. 2009, 25, 911-918. [CrossRef]

12. Mo, P.K.; Coulson, N.S. Exploring the communication of social support within virtual communities: a content analysis of messages posted to an online HIV/AIDS support group. Cyberpsychol. Bahav. 2008, 11, 371-374. [CrossRef] [PubMed]

13. Williams, S.L.; Mickelson, K.D. A paradox of support seeking and rejection among the stigmatized. Pers. Relatsh. 2008, 15, 493-509. [CrossRef]

14. Peterson, J.L. The challenges of seeking and receiving support for women living with HIV. Heal. Commun. 2010, 25, 470-479. [CrossRef] [PubMed]

15. Barbee, A.P.; Cunningham, M.R. An experimental approach to social support communications: Interactive coping in close relationships. Ann. Int. Commun. Assoc. 1995, 18, 381-413. [CrossRef]

16. Mortenson, S.T. Interpersonal trust and social skill in seeking social support among Chinese and Americans. Commun. Res. 2009, 36, 32-53. [CrossRef]

17. Org, U. UNAIDS Global Update Report. Available online: http://www.unaids.org/en/resources/ documents/2016/Global-AIDS-update-2016 (accessed on 20 December 2016). 
18. Statistics Overview: HIV in the United States: At a Glance. Available online: https://www.cdc.gov/hiv / default.html (accessed on 20 December 2016).

19. Burleson, B.R.; MacGeorge, E.L. Supportive communication. Handb. Interpers. Commun. 2002, 3, $374-424$.

20. High, A.C.; Dillard, J.P. A review and meta-analysis of person-centered messages and social support outcomes. Commun. Stud. 2012, 63, 99-118. [CrossRef]

21. Cutrona, C.E.; Suhr, J.A. Controllability of stressful events and satisfaction with spouse support behaviors. Commun. Res. 1992, 19, 154-174. [CrossRef]

22. Burleson, B.R. The experience and effects of emotional support: What the study of cultural and gender differences can tell us about close relationships, emotion, and interpersonal communication. Pers. Relatsh. 2003, 10, 1-23. [CrossRef]

23. Feng, B.; MacGeorge, E.L. The influences of message and source factors on advice outcomes. Commun. Res. 2010, 37, 553-575. [CrossRef]

24. Rains, S.A.; Peterson, E.B.; Wright, K.B. Communicating social support in computer-mediated contexts: A meta-analytic review of content analyses examining support messages shared online among individuals coping with illness. Commun. Monogr. 2015, 82, 403-430. [CrossRef]

25. Holmstrom, A.J. What Helps-and What Doesn't-When Self-Esteem is Threatened?: Retrospective Reports of Esteem Support. Commun. Stud. 2012, 63, 77-98. [CrossRef]

26. Burleson, B.R. Understanding the outcomes of supportive communication: A dual-process approach. J. Soc. Pers. Relatsh. 2009, 26, 21-38. [CrossRef]

27. High, A.C.; Solomon, D.H. Communication channel, sex, and the immediate and longitudinal outcomes of verbal person-centered support. Commun. Monogr. 2014, 81, 439-468. [CrossRef]

28. Bodie, G.D.; Burleson, B.R.; Holmstrom, A.J.; McCullough, J.D.; Rack, J.J.; Hanasono, L.K.; Rosier, J.G. Effects of Cognitive Complexity and Emotional Upset on Processing Supportive Messages: Two Tests of a Dual-Process Theory of Supportive Communication Outcomes. Hum. Commun. Res. 2011, 37, 350-376. [CrossRef]

29. Caughlin, J.P.; Brashers, D.E.; Ramey, M.E.; Kosenko, K.A.; Donovan-Kicken, E.; Bute, J.J. The message design logics of responses to HIV disclosures. Human Commun. Res. 2008, 34, 655-684. [CrossRef]

30. Scott, A.M.; Caughlin, J.P.; Donovan-Kicken, E.; Mikucki-Enyart, S.L. Do message features influence responses to depression disclosure? A message design logics perspective. West. J. Commun. 2013, 77, 139-163. [CrossRef]

31. Derlega, V.J.; Winstead, B.A.; Oldfield, E.C.; Barbee, A.P. Close relationships and social support in coping with HIV: A test of sensitive interaction systems theory. AIDS Behav. 2003, 7, 119-129. [CrossRef] [PubMed]

32. Smith, R.; Rossetto, K.; Peterson, B.L. A meta-analysis of disclosure of one's HIV-positive status, stigma and social support. AIDS Care 2008, 20, 1266-1275. [CrossRef] [PubMed]

33. Veinot, T. "A lot of people didn't have a chance to support us because we never told them" Stigma management, information poverty and HIV/AIDS information/help networks. Proc. Assoc. Inf. Sci. Technol. 2009, 46, 1-20. [CrossRef]

34. DeHaan, S.; Kuper, L.E.; Magee, J.C.; Bigelow, L.; Mustanski, B.S. The interplay between online and offline explorations of identity, relationships, and sex: A mixed-methods study with LGBT youth. J. Sex Res. 2013, 50, 421-434. [CrossRef] [PubMed]

35. Rains, S.A. The implications of stigma and anonymity for self-disclosure in health blogs. Heal. Commun. 2014, 29, 23-31. [CrossRef] [PubMed]

36. Bockting, W.O.; Miner, M.H.; Swinburne Romine, R.E.; Hamilton, A.; Coleman, E. Stigma, mental health, and resilience in an online sample of the US transgender population. Am. J. Public Heal. 2013, 103, 943-951. [CrossRef] [PubMed]

37. Lawlor, A.; Kirakowski, J. Online support groups for mental health: A space for challenging self-stigma or a means of social avoidance? Comput. Hum. Behav. 2014, 32, 152-161. [CrossRef]

38. Miller, E.D. Content analysis of select YouTube postings: Comparisons of reactions to the Sandy Hook and Aurora Shootings and Hurricane Sandy. Cyberpsychol. Behav. Social Netw. 2015, 18, 635-640. [CrossRef] [PubMed]

39. Wang, Y.C.; Kraut, R.; Levine, J.M. To stay or leave?: The relationship of emotional and informational support to commitment in online health support groups. In Proceedings of the ACM 2012 conference on Computer Supported Cooperative Work, Seattle, WA, USA, 11-15 February 2012; pp. 833-842. 
40. Lai, T.Y.; Peirce, A. Analyzing Online Public Support Groups for People Living with HIV/AIDS. In Proceedings of the AMIA Annual Symposium Proceedings Archive, 10-14 November 2007; p. 1022.

41. Support Groups. Available online: https://www.supportgroups.com/ (accessed on 1 December 2016).

42. PozForums. Available online: http://forums.poz.com/ (accessed on 1 December 2016).

43. MedHelp. Available online: https://www.medhelp.org/ (accessed on 1 December 2016).

44. HealthBoards. Available online: https://www.healthboards.com/ (accessed on 1 December 2016).

45. Herring, S.C.; Stoerger, S. Gender and (a) nonymity in computer-mediated communication. In The Handbook of Language, Gender, and Sexuality, 2nd ed.; Holmes, J., Meyerhoff, M., Ehrlich, S., Eds.; Wiley-Blackwell Publishing: Hoboken, NJ, USA, 2014.

46. Snow, R.; O'Connor, B.; Jurafsky, D.; Ng, A.Y. Cheap and fast-But is it good?: Evaluating non-expert annotations for natural language tasks. In Proceedings of the Conference on Empirical Methods in Natural Language Processing, Honolulu, HI, USA, 25-27 October 2008; pp. 254-263.

(c) 2018 by the authors. Licensee MDPI, Basel, Switzerland. This article is an open access article distributed under the terms and conditions of the Creative Commons Attribution (CC BY) license (http://creativecommons.org/licenses/by/4.0/). 